\title{
Catalytic aspects of a copper(II) complex: biological oxidase to oxygenase activity
}

\author{
BISWAJIT CHOWDHURY ${ }^{\mathrm{a}}$, MILAN MAJI ${ }^{\mathrm{c}}$ and BHASKAR BISWAS ${ }^{\mathrm{a}, \mathrm{b}, *}$ \\ ${ }^{a}$ Department of Chemistry, Raghunathpur College, Purulia, West Bengal 723 133, India \\ ${ }^{b}$ Department of Chemistry, Surendranath College, 24/2 M G Road, Kolkata, West Bengal 700 009, India \\ ${ }^{c}$ Department of Chemistry, National Institute of Technology, Mahatma Gandhi Avenue, Durgapur, West Bengal \\ 713 209, India \\ E-mail: mr.bbiswas@rediffmail.com
}

MS received 19 February 2017; revised 30 August 2017; accepted 7 September 2017; published online 3 October 2017

\begin{abstract}
A coper(II) complex, $\left[\mathrm{Cu}(\mathrm{dpa})_{2}(\mathrm{OAc})\right]\left(\mathrm{ClO}_{4}\right)(\mathbf{1})\left[\mathrm{dpa}=2,2^{\prime}\right.$-dipyridylamine; $\mathrm{OAc}=$ acetate $]$, has been synthesized and crystallographically characterized. X-ray structure analysis revealed that this mononuclear $\mathrm{Cu}$ (II) complex crystallizes as a rare class of hexa coordination geometry named bicapped square pyramidal geometry with $P 21 / \mathrm{c}$ space group. This copper complex displays excellent catalytic efficiency, $\mathrm{k}_{\mathrm{cat}} / \mathrm{K}_{\mathrm{M}}\left(\mathrm{h}^{-1}\right)=$ $6.17 \times 10^{5}$ towards the oxidative coupling of 2 -aminophenol (2-AP) to aminophenoxazin-3-one. Further, upon stoichiometric addition of copper(II) complex to 3,5-DTBC in presence of molecular oxygen in ethanol medium, the copper complex affords predominantly extradiol cleavage products along with a small amount of benzoquinone and a trace amount of intradiol cleavage products at a rate, $\mathrm{k}_{\mathrm{obs}}=1.09 \times 10^{-3} \mathrm{~min}^{-1}$, which provide substantial evidence for the oxygen activation mechanism. This paper presents a novel addition of a copper(II) complex having the potential to mimic the active site of phenoxazinone synthase and catechol dioxygenase enzymes with significant catalytic efficiency.
\end{abstract}

Keywords. Copper(II); crystal structure; phenoxazinone synthase activity; catechol dioxygenase; bio-mimetic chemistry.

\section{Introduction}

Over the past few decades, biochemical oxidation reactions have significantly stimulated the coordination chemists to design various metal complexes as structural and functional mimic of the active site of different metalloproteins and metalloenzymes. ${ }^{1-3}$ Bio-inspired catalysis mediated by different copper proteins and enzymes include primarily dioxygen transport (hemocyanin, $\mathrm{Hc}$ ), ${ }^{4}$ aromatic ring oxidations (tyrosinase, $\mathrm{Tyr},{ }^{5}$ catechol oxidase, ${ }^{6}$ and quercetin-2,3-dioxygenase, ${ }^{7-9}$ the biogenesis of neurotransmitters and peptide hormones (dopamine- $\beta$-monooxygenase, $\mathrm{D} \beta \mathrm{M},{ }^{10}$ and peptidylglycine $\alpha$-amidating monooxygenase, PHM, ${ }^{11,12}$ hydrogen peroxide generation (galactose and glyoxal oxidases, ${ }^{13-18}$ iron homeostasis (ceruloplasmin3 and Fet $3 p,{ }^{19-21}$ and methane oxidation (particulate methane monoxygenase, pMMO). ${ }^{22-25}$ A prominent member of

\footnotetext{
*For correspondence
}

these copper proteins is phenoxazinone synthase which is a copper-containing oxidase that catalyzes the coupling of 2-aminophenols to form the 2-aminophenoxazinone chromophore. This reaction constitutes the final step in the biosynthesis of the potent antineoplastic agent actinomycin. ${ }^{26-29}$ On the other hand, catechol dioxygenases of intradiol class utilizes a non-heme iron(III) cofactor in catalyzing the cleavage of the carboncarbon bond between the two catechol oxygens; and the extradiol dioxygenases utilize a nonheme iron(II) cofactor in catalyzing the cleavage of the carbon-carbon bond adjacent to the catechol oxygens. ${ }^{30,31}$ In the last decade, Youngme et al., and Choudhury et al., produced same $\mathrm{Cu}(\mathrm{II})$-dipyridyl complex using different reaction methodology. ${ }^{32}$ Here we introduce a copper(II)dipyridylamine complex $\left[\mathrm{Cu}(\mathrm{dpa})_{2}(\mathrm{OAc})\right]\left(\mathrm{ClO}_{4}\right)$ (1) $\left[\right.$ dpa $=2,2^{\prime}$-dipyridylamine; OAc $=$ acetate $]$, with potential ability to mimic the functional sites of phenoxazinone synthase enzyme with $k_{\text {cat }}\left(\mathrm{h}^{-1}\right)=1.83 \times 10^{3}$ and catechol dioxygenase enzyme with the

Electronic supplementary material: The online version of this article (doi:10.1007/s12039-017-1379-y) contains supplementary material, which is available to authorized users. 
decomposition rate, $1.09 \times 10^{-3} \mathrm{~min}^{-1}$, respectively. Coordinative unsaturation of the $\mathrm{Cu}$ (II) centre in ethanol medium facilitates the formation of substrate-enzyme adduct and account in favour of such oxidase to oxygenase activity.

\section{Experimental}

\subsection{Materials}

High purity 2, 2'-dipyridylamine (Aldrich, UK), copper(II) perchlorate hexahydrate (Fluka, Germany), sodium acetate (E. Merck, India), 2-aminophenol (E. Merck, India), 3,5di-tert-butylcatechol (Sigma Aldrich Corporation, St. Louis, MO, USA) were obtained from commercial sources and used as purchased. All other chemicals and solvents were of analytical grade and were used as received without further purification.

Caution! Perchlorate salts of metal ions are potentially explosive, especially in the presence of organic ligands. Only a small amount of material should be prepared and it should be handled with care.

\subsection{Synthesis of $\left[\mathrm{Cu}(\mathrm{dpa})_{2}(\mathrm{OAc})\right]\left(\mathrm{ClO}_{4}\right)(\mathrm{I})$}

The copper(II) complex was synthesized by addition of aqueous solution of dipyridylamine $(0.3420 \mathrm{~g}, 2 \mathrm{mmol})$ into a solution of $\left.\mathrm{Cu}\left(\mathrm{ClO}_{4}\right)_{2} \cdot 6 \mathrm{H}_{2} \mathrm{O}(0.3650 \mathrm{~g}, 1 \mathrm{mmol})\right]$ in the same solvent $(20 \mathrm{~mL})$ keeping the solution on a magnetic stirrer with stirring. Then solid sodium acetate $(0.0820 \mathrm{~g}, 1$ $\mathrm{mmol}$ ) was added in solid into the blue solution and stirring continued to $30 \mathrm{~min}$ more. The blue solutions were turned into green and the supernatant liquids were kept in air for slow evaporation. After 7-10 days the fine microcrystalline compound was separated out and washed with hexane and dried in vacuo over silica gel indicator. The spectroscopic measurements and elemental analyses confirm the structural formation of the complex. Yield $=\sim 0.28 \mathrm{~g},(\sim 77 \%$ based on metal salt). Anal. calc. (\%) $\mathrm{C}_{22} \mathrm{H}_{22} \mathrm{~N}_{6} \mathrm{ClO}_{6} \mathrm{Cu}: \mathrm{C}$, 46.73; H, 3.92; N, 14.86; Found(\%): C, 46.69; H, 3.88; N, 14.89. Selected IR bands $\left(\mathrm{KBr}\right.$ pellet, $\left.\mathrm{cm}^{-1}\right): 3321(\mathrm{~m})$, 1637(s), 1604(s),1423(m), 1378(s), 1095(s). UV-Vis ( $\lambda, \mathrm{nm}$; $10^{-4} \mathrm{M}, 1 \mathrm{~cm}$ cell length, abs, ethanol): 298(1.86), 725745(0.00180) (broad band); ESI-MS (MeCN): m/z, 406.10 $\left(\left[\mathrm{Cu}(\mathrm{dpa})_{2}\right]-\mathrm{H}^{+}\right)$; (Calc. 406.09).

\subsection{Physical measurements}

Infrared spectrum $(\mathrm{KBr})$ was recorded with a FTIR-8400S SHIMADZU spectrophotometer in the range $400-3600 \mathrm{~cm}^{-1}$. ${ }^{1} \mathrm{H}$ NMR spectrum in DMSO- $d^{6}$ was obtained on a Bruker Avance $300 \mathrm{MHz}$ spectrometer at $25^{\circ} \mathrm{C}$ and was recorded at 299.948 MHz. Ground-state absorption measurements were made with a Jasco model V-730 UV-Vis spectrophotometer. Elemental analyses were performed on a Perkin Elmer 2400
CHN microanalyser. Electrospray ionization (ESI) mass spectrum was recorded on a Q-TOF MicroTM Mass Spectrometer. The electrochemical studies were carried out using Cyclic voltammograms were recorded in $\mathrm{CH}_{3} \mathrm{CN}$ solutions containing $0.1 \mathrm{M} \mathrm{TBAP}$ at $25^{\circ} \mathrm{C}$ using a three-electrode configuration (Pt working electrode, $\mathrm{Pt}$ counter electrode, $\mathrm{Ag} / \mathrm{AgCl}$ reference) and a PC-controlled PAR model 273A electrochemistry system. All the experimental solutions were degassed for 30 min with high-purity argon gas before any cyclic voltammetry of a sample was done. The Electron Paramagnetic Resonance (EPR) spectrum was recorded on a Bruker EMX-X band spectrometer.

\subsection{Crystal structure determination and refinement}

Single crystal X-ray diffraction data of the copper(II) complex were collected using a Rigaku XtaLABmini diffractometer equipped with Mercury CCD detector. The data were collected with graphite monochromated Mo-K $\alpha$ radiation $(\lambda=$ $0.71073 \AA$ ) at $293 \mathrm{~K}$ using $\omega$ scans. The data were reduced using Crystal Clear suite $2.0^{33}$ and the space group determination was done using Olex2. The structure was resolved by direct method and refined by full-matrix least-squares procedures using the SHELXL-2014/7 ${ }^{34}$ software package through the OLEX2 suite. ${ }^{35}$ The crystallographic bond distance and bond angle are given in Table 1 and Table S1 (in Supplementary Information).

\subsection{Catalytic oxidation of 2-aminophenol}

In order to examine the penoxazinone synthase activity, $1 \times 10^{-3} \mathrm{M}$ solution of $\mathbf{1}$ in $\mathrm{EtOH}$ was treated with 10 equiv.

Table 1. Crystallographic refinement parameters of $\left[\mathrm{Cu}(\mathrm{dpa})_{2}(\mathrm{OAc})\right]\left(\mathrm{ClO}_{4}\right)(\mathbf{1})$.

\begin{tabular}{lc}
\hline Parameters & $\mathrm{Cu}(\mathrm{II})$ compound \\
\hline Empirical formula & $\mathrm{C}_{22} \mathrm{H}_{21} \mathrm{~N}_{6} \mathrm{O}_{6} \mathrm{ClCu}$ \\
Formula weight & 564.44 \\
Temperature $(\mathrm{K})$ & 293 \\
Crystal system & Monoclinic \\
Space group & $P 2_{1} / c$ \\
$\mathrm{a}(\AA)$ & $13.885(12)$ \\
$\mathrm{b}(\AA)$ & $7.899(7)$ \\
$\mathrm{c}(\AA)$ & $22.202(18)$ \\
Volume $\left(\AA^{3}\right)$ & $2582.7(2)$ \\
$\mathrm{Z}$ & 4 \\
$\rho\left(\mathrm{g} \mathrm{cm}^{-3}\right)$ & 1.541 \\
$\mu\left(\mathrm{mm}^{-1}\right)$ & 1.058 \\
$\mathrm{~F}(000)$ & 1156 \\
$\theta$ ranges $\left(^{\circ}\right)$ & $3.1^{\circ}$ to $27.50^{\circ}$ \\
$\mathrm{R}_{\text {int }}$ & 0.038 \\
$\mathrm{R}($ reflections) & 15670 \\
$\omega R 2($ reflections $)$ & 5578 \\
Final R indices & $0.0634,0.1929$ \\
Largest peak and hole $\left(\mathrm{eA}^{\circ-3}\right)$ & $0.77,-0.44$ \\
\hline
\end{tabular}


of 2-aminophenol (2-AP) under aerobic conditions at room temperature. Absorbance vs. wavelength (wavelength scans) of the solution was recorded at a regular time interval of $15 \mathrm{~min}$ for aminophenol oxidation in the wavelength range 300-800 nm. Kinetic experiments were performed spectrophotometrically ${ }^{26-28}$ with $\mathrm{Cu}(\mathrm{II})$ complex and $2-\mathrm{AP}$ in EtOH at $25^{\circ} \mathrm{C}$ for aminophenol oxidation activity. $0.04 \mathrm{~mL}$ of the complex solution, with a constant concentration of $1 \times 10^{-3} \mathrm{M}$, was added to $2 \mathrm{~mL}$ of 2-AP of a particular concentration (varying its concentration from $1 \times 10^{-3} \mathrm{M}$ to $1 \times 10^{-2} \mathrm{M}$ ) to achieve the ultimate concentration of the complex as $1 \times 10^{-3} \mathrm{M}$. The conversion of 2-aminophenol to 2-aminophenoxazine-3-one was monitored with time at $433 \mathrm{~nm}$ (time scan) ${ }^{28}$ in EtOH. To determine the dependence of rate on substrate concentration, kinetic analyses were performed in triplicate. Effect of catalyst concentration on the reaction rate for the catalytic aminophenol oxidation in EtOH medium was determined by varying the concentration of copper(II) complex $\left(5 \times 10^{-3} \mathrm{M}\right.$ to $\left.5 \times 10^{-4} \mathrm{M}\right)$ with a constant concentration $\left(1 \times 10^{-2} \mathrm{M}\right)$ of each substrate. Here, the kinetic analyses were also performed in triplicate.

\subsection{Catechol dioxygenase activity of the coper(II)-dipyridylamine complex}

To investigate the catechol dioxygenase activity of the complex, a $10^{-3} \mathrm{M}$ solution of $\mathbf{1}$ in ethanol (EtOH) solvent was treated with a $10^{-3} \mathrm{M}$ solution of 3,5-di-tert-butylcatechol (DTBC) in oxygen saturated ethanol medium at room temperature. Absorbance vs. wavelength (wavelength scans) of the solution was recorded at regular time intervals for $6 \mathrm{~h}$ in the wavelength range $200-900 \mathrm{~nm} .{ }^{36}$ It may be noted here that a blank experiment without catalyst did not show the formation of any cleavage products up to $12 \mathrm{~h}$ in EtOH. The solvent was equilibrated at the atmospheric pressure of $\mathrm{O}_{2}$ at $25^{\circ} \mathrm{C}$ using a known procedure with modifications. ${ }^{37}$ Investigation of dioxygen reactivity of the in situ generated $\mathrm{Cu}$ (II)-catecholate adduct was carried out in oxygen saturated ethanol medium at $25^{\circ} \mathrm{C}$. Kinetic analyses ${ }^{36}$ of the catechol cleavage reactions were carried out by timedependent measurement of the disappearance of the lower energy $\mathrm{DBC}^{2-}$-to-Cu(II) LMCT band at $824 \mathrm{~nm}$ by exposing to molecular oxygen.

\subsection{Determination of 3,5-di-tert-butyl catechol cleavage products}

$0.2260 \mathrm{~g}(0.04 \mathrm{mmol})$ of the $\mathrm{Cu}(\mathrm{II})$ complex was reacted with $0.088 \mathrm{~g}(0.04 \mathrm{mmol})$ of DTBC in an oxygen saturated ethanol $(100 \mathrm{~mL})$ at ambient condition and then allowed to stir for $12 \mathrm{~h}$. The reddish brown solution slowly turned to green. The residue was then treated with $15 \mathrm{~mL}$ of $3 \mathrm{M}$ $\mathrm{HCl}$ and the catechol cleavage products were extracted with diethylether $(3 \times 10 \mathrm{~mL})$ and dried over sodium sulfate. The catechol cleavage products were analyzed by ESI-MS and were quantified by ${ }^{1} \mathrm{H}$ NMR spectroscopy. ${ }^{1} \mathrm{H}$ NMR data for 3,5-di-tert-butyl catechol cleavage products $(500$
$\left.\mathrm{MHz}, \mathrm{CDCl}_{3}\right): \delta=3$, 5-di-tert-butyl-2-pyrone: $6.09(\mathrm{~m}, 2 \mathrm{H})$; 4,6- di-tert-butyl-2-pyrone: $7.11(\mathrm{~d}, 1 \mathrm{H}), 7.24(\mathrm{~d}, 1 \mathrm{H})$; 3,5di-tert-butylbenzoquinone: $6.19(\mathrm{~d}, 1 \mathrm{H}), 6.74(\mathrm{~d}, 1 \mathrm{H})$; 3,5-ditert-butyl-5-(carboxymethyl)-2-furanone: 6.84 (s, 1H).

\section{Results and Discussion}

\subsection{Synthesis and formulation of the Cu(II)-dpa complex (1)}

The copper(II) complex was synthesized by addition of 2, 2'-dipyridylamine to a solution of $\mathrm{Cu}\left(\mathrm{ClO}_{4}\right)_{2} \cdot 6 \mathrm{H}_{2} \mathrm{O}$ in water followed by the addition of sodium acetate $(\mathrm{NaOAc})$ at room temperature (Scheme 1). The structure was determined by routine spectroscopic techniques including single crystal X-ray diffraction analysis.

\subsection{Description of the crystal structure}

The X-ray crystal structure analysis of copper(II) complex reveals that it crystallizes in monoclinic crystal system with $P 2_{1} / \mathrm{c}$ space group. An ORTEP of the copper(II) complex is shown in Figure 1. The crystallographic structural parameters are given in Table 1 and bond angles, and bond distances are given in Table S1. Monocationic $\left[\mathrm{Cu}(\mathrm{dpa})_{2}(\mathrm{OAc})\right]^{+}$unit exists in a rare class of six coordination geometry named bicapped square pyramidal geometry and the residual cationic charge is counterbalanced by a perchlorate ion. This copper(II) complex resembles to previously reported bicapped square pyramidal chromophore, $\left[\mathrm{Cu}(\mathrm{bpy})_{2}\right.$ $\left.\left(\mathrm{O}_{2} \mathrm{NO}\right)\right]\left(\mathrm{NO}_{3}\right)^{38}$ and this structure is known as a rare class of coordination geometry in the scientific literature. The square plane contains N1,N2 (dpa), N4(other dpa) atoms and $\mathrm{O} 1$ atom of acetate ligand [Cu1-N1,

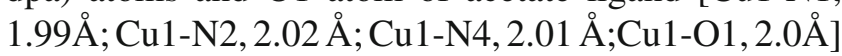
while $\mathrm{N} 2$ (other dpa) and O2(acetate) atoms occupy

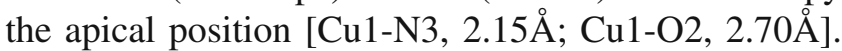
Though there are two $\mathrm{Cu}-\mathrm{O}$ bonds (axial and equatorial) around the $\mathrm{Cu}$ centre but $\mathrm{Cu} 1-\mathrm{O} 2$ bond gets axially elongated due to Jahn-Teller distortion. ${ }^{39}$ In searching for the origin of the existence of this unusual geometry of the copper(II) complex in the solid state, we closely observe the role of H-bonding interaction. In the crystalline state of $\mathrm{Cu}$ (II) complex, perchlorate anion has a substantial role to rotate the pyridine rings of the dipyridyl amine. The oxygen atoms of the $\mathrm{ClO}_{4}^{-}$ ion act as donor centres and $\mathrm{H}$-atoms of the pyridine rings as well as secondary amines behave as acceptors

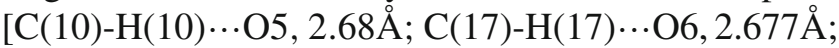
$\mathrm{C}(17)-\mathrm{H}(17) \cdots \mathrm{O} 4,2.601 \AA ; \mathrm{C}(8)-\mathrm{H}(8) \cdots \mathrm{O} 3,2.635 \AA$;

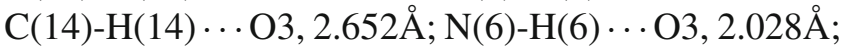




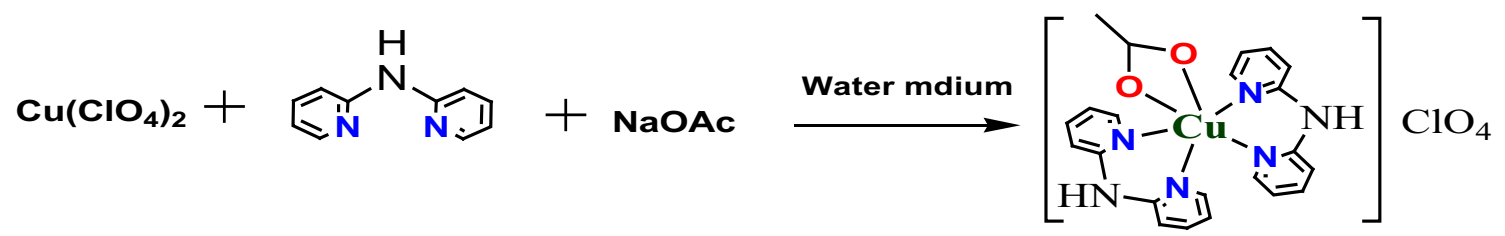

Scheme 1. Preparative procedure for the $\mathrm{Cu}(\mathrm{II})$ complex.

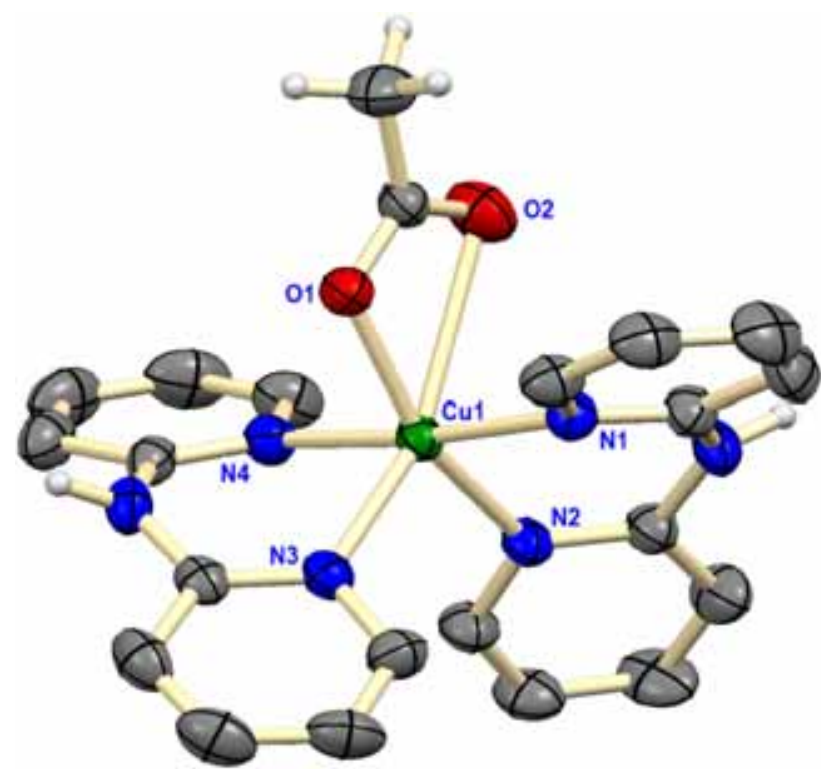

Figure 1. An ORTEP diagram of $\mathrm{Cu}$ (II)-dpa complex (30\% ellipsoid probability).

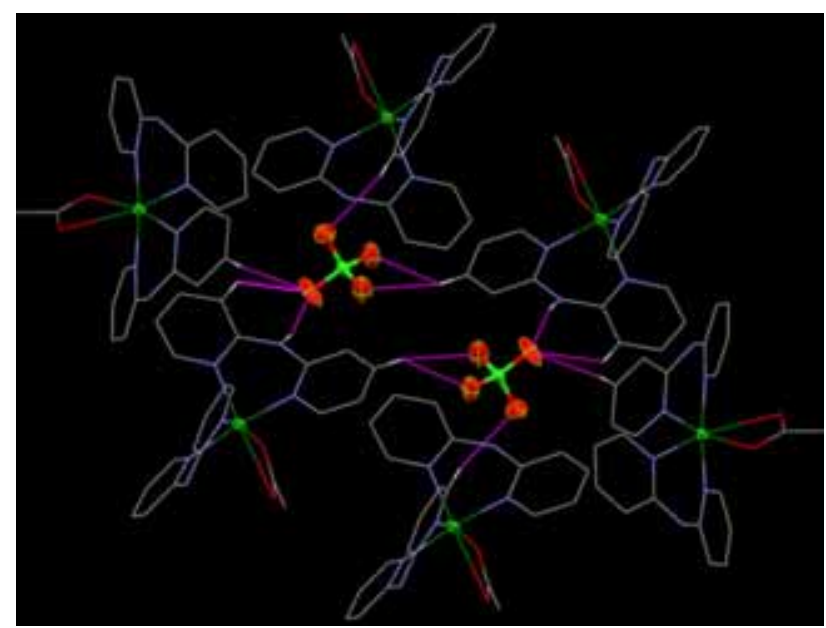

Figure 2. Perchlorate ion mediated 3D crystalline architechture through $\mathrm{C} / \mathrm{N}-\mathrm{H} \ldots \mathrm{O}$ interaction in solid state.

Figure 2, Table S2 in Supplementary Information] to form a 3D architecture through $\mathrm{C}-\mathrm{H} \cdots \mathrm{O} / \mathrm{N}-\mathrm{H} \cdots \mathrm{O}$ interactions along $b$ axis.

\subsection{Electronic, EPR and electrochemical characterization}

The solution integrity of the copper complex has been performed through UV-Vis and EPR spectral analysis. The UV-Vis spectrum in ethanol medium at room temperature shows a series of high intensity transitions in the range of 225 to 238 and $295 \mathrm{~nm}$ which are originated from the intraligand electronic transitions (Figure S1). A very broad low energy transition centered at 741 $\mathrm{nm}$ (Figure S1 in Supplementary Information), which is assigned to the ligand field transition for the copper(II) complex. The X-band EPR spectrum of the copper complex (Figure S2 in SI) at low temperature (LT, 77K) was recorded in frozen $\mathrm{MeCN}$ solution (Figure S2 (Left)) and in powder state at $77 \mathrm{~K}$ (Figure S2 (Right) in SI) to examine the geometry of copper center in $\mathbf{1}$. The bicapped square pyramidal environment was also confirmed from the presence of four lines in the LT spectrum and suggested the existence of a single species (Figure S2).

We have also examined the electrochemical behaviour of this copper(II) complex in ethanol at RT. The reduction and oxidation potentials for $\mathrm{Cu}$ (II)-dpa complex was observed, respectively, at -773 and +42 $\mathrm{mV}$ (Figure S3 in SI) at the scan rate of $20 \mathrm{mV}$ $\mathrm{s}^{-1}$. The high value of reduction potential suggests that the reduction is quite difficult for central $\mathrm{Cu}(\mathrm{II})$ ion.

\subsection{Catalytic oxidation of 2-aminophenol}

The phenoxazinone synthase activity of the copper(II) complex was studied using 2-aminophenol (2-AP) as a convenient model substrate, in air saturated ethanol solvent at room temperature $\left(25^{\circ} \mathrm{C}\right)$. For this purpose, a $1 \times 10^{-3} \mathrm{M}$ solution of the copper(II)-dipyridylamine complex was treated with $1 \times 10^{-2} \mathrm{M}$ (10 equiv.) of 2 -AP and the course of the reaction was followed by recording the UV-Vis spectra of the mixture at an interval of 15 $\min$ for $3 \mathrm{~h}$.

Spectral bands at 225-238, 295 and $741 \mathrm{~nm}$ appeared in the electronic spectrum of the copper complex in methanol, whereas 2-AP showed a single band at 267 $\mathrm{nm}$. As the reaction proceeded, there was a gradual 


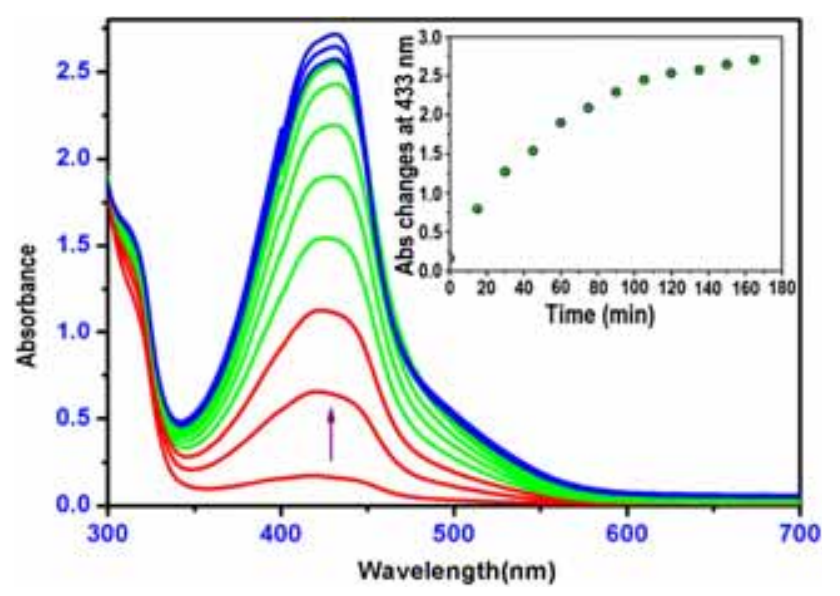

Figure 3. Increase of aminophenoxazinone band at $433 \mathrm{~nm}$ after addition of 10 equivalents of 2-AP to a $\mathrm{Cu}$ (II) solution in EtOH medium. The spectra were recorded after every $9 \mathrm{~min}$. Inset: Plot of Abs versus time.

decrease in intensity of the band at $267 \mathrm{~nm}^{26}$ and an initial new broad band centered at $433 \mathrm{~nm}$ with increasing intensity was formed (Figure 3), which indicated the formation of the respective phenoxazinone species. ${ }^{26-29}$ The phenoxazinone was purified by column chromatography and isolated in high yield ( $81.6 \%$ for 1$)$ by slow evaporation of the eluant. The product was identified by ${ }^{1} \mathrm{H}$ NMR spectroscopy. ${ }^{1} \mathrm{H} \mathrm{NMR}\left(\mathrm{CDCl}_{3}, 300 \mathrm{MHz}\right.$, $\delta_{\mathrm{H}}: 7.62(\mathrm{~m}, 1 \mathrm{H}), 7.48(\mathrm{~m}, 3 \mathrm{H}), 6.41(\mathrm{~s}, 1 \mathrm{H}), 6.30(\mathrm{~s}$, $1 \mathrm{H})$.

Kinetic studies were performed to understand the extent of the efficiency. The kinetics of oxidation of 2-AP were determined by the method of initial rates and involved monitoring the growth of the phenoxazinone band at $433 \mathrm{~nm}$ as a function of time (Figure S4 in SI). ${ }^{28,29}$ The plot of rate constants versus concentration of the substrate were also analyzed on the basis of the Michaelis-Menten approach of enzymatic kinetics to get the values of the kinetics parameters, $\mathrm{V}_{\max } 5.11 \times 10^{-4}$ $\left(\mathrm{Sd}\right.$. Error. $\left.7.78 \times 10^{-5}\right), \mathrm{K}_{\mathrm{M}}=2.98 \times 10^{-3}(\mathrm{Sd}$. Error $9.14 \times 10^{-3}$ ) and $k_{\text {cat }}=1.83 \times 10^{3}$. The observed rate constant versus substrate concentration plot for copper(II)-dipyridylamine complex in EtOH is shown in Figure S4 (in SI).

The high catalytic efficiency value $\left(k_{\text {cat }} / \mathrm{K}_{\mathrm{M}}=\right.$ $2.09 \times 10^{5}$ ) for copper(II) complex also indicates its high reactivity towards aminophenol oxidation. We also investigate the effect of catalyst concentration on reaction rate and the rate of catalytic oxidation increase with increasing the concentration of copper(II)dipyridylamine complex in a linear manner. Reuse of this copper(II)-dipyridylamine catalyst (Figure S9) for aminophenol oxidation was also examined under similar reaction conditions after completion of catalytic oxidation. The reused copper(II)-dipyridylamine catalyst exhibited no change in reactivity after four cycles also. In order to make a comparison of the phenoxazinone activity between our copper-dpa complex and the reported copper(II) complex, $\left[\mathrm{Cu}(\mathrm{bpy})_{2}\left(\mathrm{O}_{2} \mathrm{NO}\right)\right]\left(\mathrm{NO}_{3}\right)$ of the same class, we performed phenoxazinone synthase activity for the both complexes under similar reaction conditions. We find that $\mathrm{Cu}$ (II)-dpa complex exhibits better catalytic efficiency towards the oxidative coupling of 2-aminophenol than the reported copper complex. $^{38}$

Though this class of catalytic oxidation reaction under aerobic condition bears special attention, we could not find enough literature reports to make a comparison between phenoxazinone synthase activity of the $\mathrm{Cu}$ (II)-dipyridylamine in the present case and previously reported works. Chaudhury et al. ${ }^{40 a}$ modelled a tetracopper complex for the catalytic aerial oxidation of 2-aminophenol to 2-amino-phenoxazine-3-one, and proposed an "on-off" mechanism of the radicals together with redox participation of the metal center behind the mimics of six-electron oxidative coupling in the catalytic function of the coppercontaining enzyme phenoxazinone synthase. Begley et al., ${ }^{40 \mathrm{~b}}$ suggested that 2-aminophenoxazinone synthesis proceeds via a sequence of three consecutive 2-electron aminophenol oxidations and that the aminophenol moiety is regenerated during the reaction sequence by facile tautomerization reactions.

In order to evaluate the mechanistic aspects of the catalytic cycle by copper(II)-dipyridylamine complex (Scheme 2) for the oxidative coupling of phenoxazinone product, mass spectral analysis of the reaction mixture in ethanol medium provides valuable information regarding the reactive species and product formed in the reaction. The mass spectrum of the reaction mixture (Figure S5 in SI) exhibits mainly the characteristic peaks at $\mathrm{m} / \mathrm{z} 213.57$ and 557.99 with isotope distribution patterns which further consolidated the corroboration respectively [(2-amino-3 $\mathrm{H}$-phenoxazine-3-ones $)+\mathrm{H}^{+}$] and $\left[\left[\mathrm{Cu}(\mathrm{dpa})_{2}(2-\mathrm{AP})\right]+\mathrm{H}^{+}\right]$. Further, the characteristic peak at $\mathrm{m} / \mathrm{z} \sim 557.99 \mathrm{~nm}$ indicates the presence of coordinated iminobenzosemiquinonato radical during the generating apx product.

\subsection{Catechol dioxygenase activity of the copper(II)-dipyridylamine complex}

The oxygenation reactions for the copper(II)-dipyridylamine complex was carried out using 3,5-di-tertbutylcatechol (DTBC) as the model substrate in biofriendly ethanol, and the advantages of using the latter as substrate are the relatively high stability of the main 


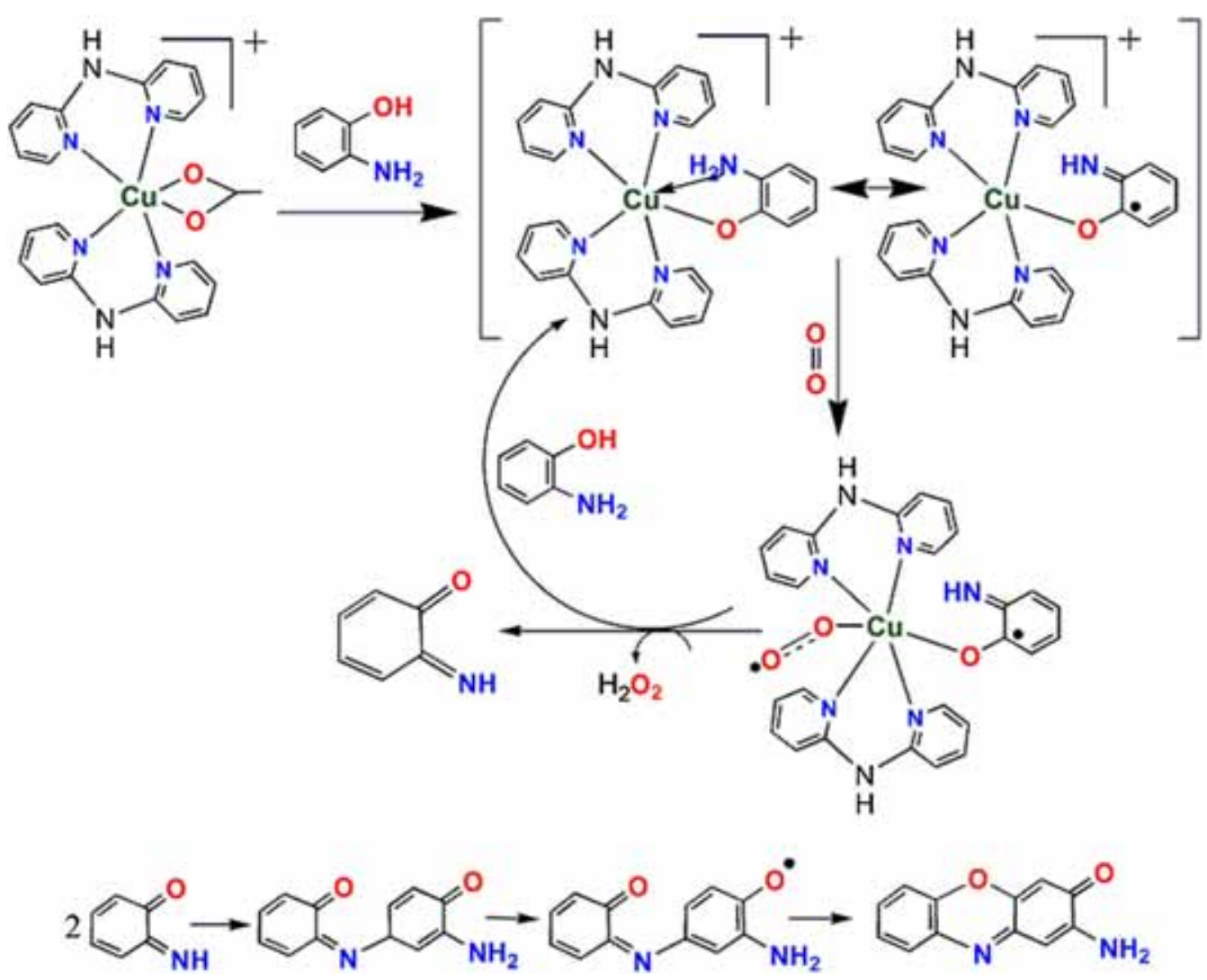

Scheme 2. Proposed mechanistic routes for aminophenol oxidation by copper(II) complex.

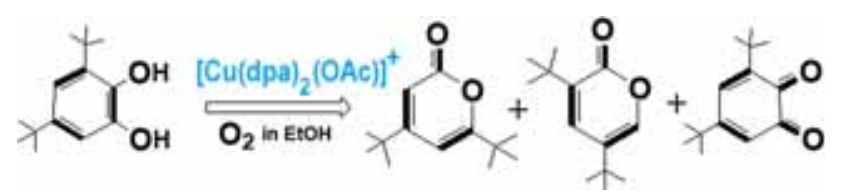

Scheme 3. Oxygenation products of DTBC for $\mathrm{Cu}(\mathrm{II})$ complex in ethanol.

cleavage product and the fast reaction of the catecholate complex with dioxygen at room temperature (Scheme 3).

The DTBC ${ }^{2-}$ adducts of $\mathrm{Cu}$ (II) complex was generated in situ in ethanol solution, and their reactivity toward $\mathrm{O}_{2}$ was investigated by monitoring the decay of the low energy $\mathrm{DTBC}^{2-}$ to $\mathrm{Cu}(\mathrm{II}) \mathrm{LMCT}$ band (Figure 4). The green solution of the in situ $\mathrm{Cu}(\mathrm{II})$ catecholate adduct reacts with dioxygen in bio-friendly ethanol medium at ambient conditions over a period of $4 \mathrm{~h}$ and two new visible bands with maximum absorption at 516 and $824 \mathrm{~nm}$ (Figure 4), were observed for the catecholate adduct of $\mathrm{Cu}$ (II) complex. The lower energy visible bands with decreasing in absorbance are attributed to $\mathrm{DTBC}^{2-}$ to-copper(II) LMCT transitions involving two different catecholate ligand orbitals. ${ }^{30,31}$ Commonly, it is seen that the energy of the LMCT transition strongly depends on the nature of the ligands

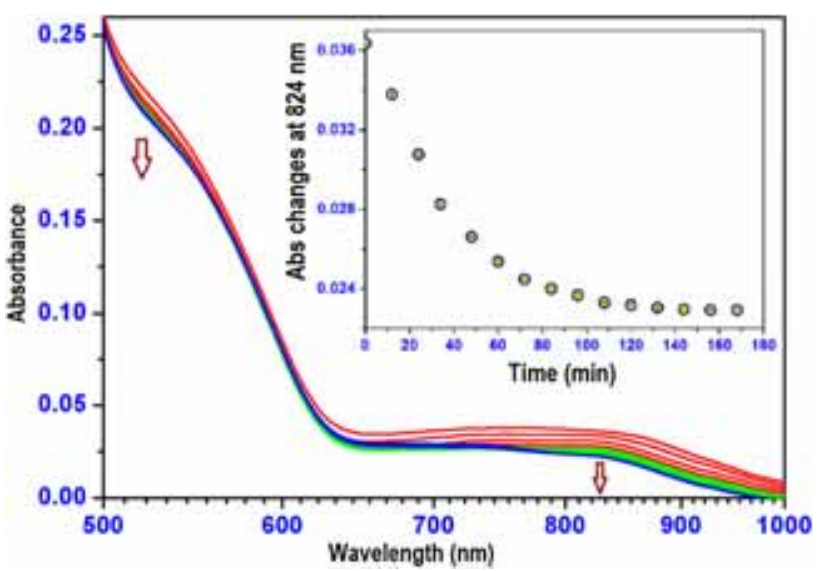

Figure 4. Absorption spectral changes during the reaction of the in situ generated adduct $\left[\mathrm{Cu}(\mathrm{dpa})_{2}(2-\mathrm{AP})\right]$ with $\mathrm{O}_{2}$ (The spectra were recorded after every $12 \mathrm{~min}$ ). Inset: Plot of Abs versus Time.

and Lewis acidity of the metal ion in the complex. ${ }^{41,42}$ The disappearance of the lower-energy catecholateto-copper(II) LMCT band (Figure 4) on oxygenation exhibits pseudo first-order kinetics, as judged from the linearity of the plot $[1+\log ($ Absorbance $)]$ versus time ${ }^{43}$ (Figure 5), and the value of $\mathrm{k}_{\mathrm{obs}}$ was obtained from the 


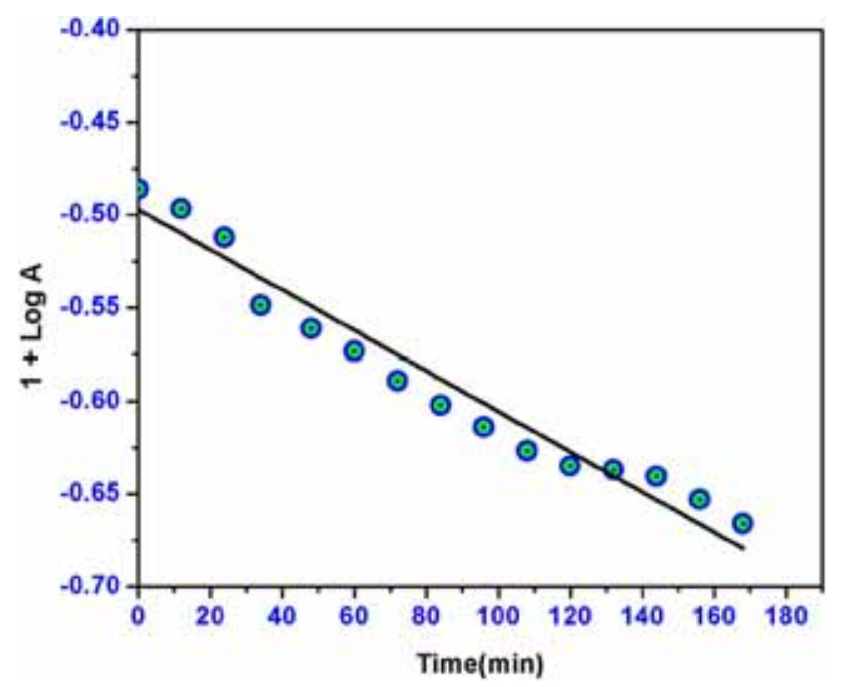

Figure 5. Plot of $[1+\log ($ Absorbance $)]$ versus time for the reaction of $\left[\mathrm{Cu}(\mathrm{dpa})_{2}(\mathrm{DBC})\right]$ with $\mathrm{O}_{2}$ at $25^{\circ} \mathrm{C}$ in $\mathrm{EtOH}$ solution. slope of the plot. The pseudo-first order rate constant was determined as $\mathrm{k}_{\mathrm{obs}}: 1.09 \times 10^{-3} \mathrm{~min}^{-1}$.

Further, the cleavage products from catechol bound $\mathrm{Cu}$ (II) species were identified and quantified by ${ }^{1} \mathrm{H}$ NMR spectroscopy (Figure S6 in SI). The distribution of catechol-derived products was found to be principally 4,6-di-tert-butyl-2-pyrone and 3,5- di-tertbutyl-2-pyrone, as extradiol cleavage products, in major amount and 3,5-di-tert-butylbenzoquinone as minor product, while 3,5-di-tert-butyl-5-(carboxymethyl)-2furanone as intradiol cleavage product was found in trace quantity. In the reaction of (Cu complex+DTBC) with $\mathrm{O}_{2}$ in ethanol, $81 \%$ of extradiol cleavage products $(42.6 \%+38.4 \%)$ were obtained along with the formation of a trace amount of intradiol cleavage product as a side product (Scheme 4). The percentage of minor oxidation product, 3,5-di-tert-butylbenzoquinone, was found to be a small one (16.8\%) also. The amount of

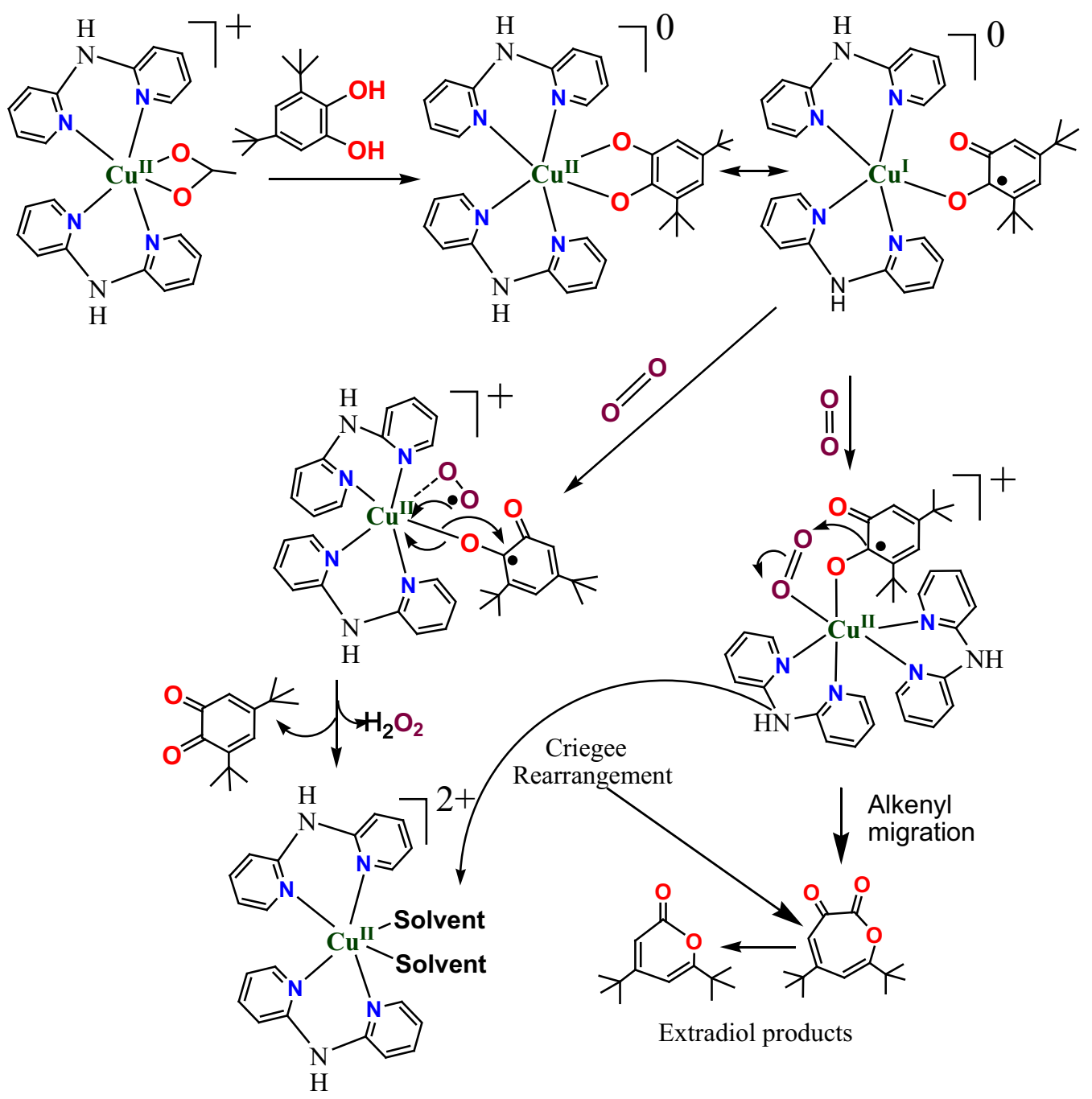

Scheme 4. Proposed mechanistic pathway for the formation of cleavage products by $\mathbf{1}$. 
organic product from catechol cleavage accounts for $\sim 95 \%$ of 3,5-di-tert-butyl catechol. The remaining 5\% was accounted as unreacted substrate.

The formation of extradiol cleavage products for the in situ catecholate adduct of the $\mathrm{Cu}$ (II) complex is expected for having a vacant coordination site on the catecholate adduct for oxygen coordination, which favors dioxygen-activation pathway. ${ }^{44-46}$ From ESI mass spectrometric analysis of the reaction mixture, it is revealed that at the primary stage 3,5-DTBC forms in situ adduct but the presence of semiquinone band $\sim 516 \mathrm{~nm}$ helps to detect DTBSQ radical. The existence of the DTBQ radical in solution during the investigation of dioxygenase activity was confirmed by the EPR signal at $\mathrm{g}=2.075(\mathrm{Cu}$ complex with 3,5-DTBC in EtOH) (Figure S7 in SI). But existence of $\mathrm{Cu}(\mathrm{I})$-semiquinone species in solution facilitates dioxygen activation mechanism and provides one electron from $\mathrm{Cu}(\mathrm{I})$ to the anti-bonding orbital of dioxygen which generates oxospecies in solution and produces extradiol cleavage products in a major amount. ${ }^{43} \mathrm{~A}$ small amount of benzoquinone indicates the natural oxidation of the substrate in solution. Probably, trace amount of intradiol catechol cleavage reaction proceeded by peroxo intermediate that underwent 1,2 -Criegee rearrangement ${ }^{4}$ to yield the intradiol catechol cleaved products analogous to the native enzyme. Earlier models have shown that the dioxygenase activity strongly depends on the nature of the ligand set and the coordination mode of the catecholate ligand. ${ }^{47-51}$ Speier et al., reported an aerobic oxidation of a (phenanthrenediolato)copper(II) complex of tmeda, which is in resonance with two valence tautomers of the (phenanthrenediolato) copper(II) and the (phenanthrenesemiquinonato) copper(I) states. ${ }^{52}$ The (phenanthrenesemiquinonato) copper(I) tautomer can bind a dioxygen molecule to form a dioxygen complex, which is decomposed to ring-cleavage products.

\section{Conclusions}

Herein, we report an isolation of a copper(II)-dipyridylamine complex, $\left[\mathrm{Cu}(\mathrm{dpa})_{2}(\mathrm{OAc})\right]\left(\mathrm{ClO}_{4}\right)$ with unusual hexa coordination geometry. X-ray structure shows that this copper complex crystallizes with $P 2_{1} / \mathrm{c}$ space group in a monoclinic system. It shows significant catalytic ability, $\mathrm{k}_{\text {cat }} / \mathrm{K}_{\mathrm{M}}\left(\mathrm{h}^{-1}\right)=6.17 \times 10^{5}$ for the oxidative coupling of 2-AP to aminophenoxazin-3-one. Upon stoichiometric addition of copper(II) complex to 3,5DTBC, two catecholate-to-Cu(II) LMCT bands (516 and $824 \mathrm{~nm}$ ) were observed and the in situ generated catecholate intermediate reacts with molecular oxygen at the rate, $\mathrm{k}_{\mathrm{obs}}=1.09 \times 10^{-3} \mathrm{~min}^{-1}$ in ethanol medium to afford predominantly extradiol cleavage products along with a small amount of benzoquinone, and a trace amount of intradiol cleavage products. The yield of cleavage products is strongly in favour of molecular oxygen activation mechanism. This paper presents a novel addition of a copper(II) complex having the potential to mimic the active site of phenoxazinone synthase and catechol dioxygenase enzyme with significant catalytic efficiency.

\section{Supplementary Information (SI)}

CCDC 1513638 contains the supplementary crystallographic data for 1 . These data can be obtained free of charge via http://www.ccdc.cam.ac.uk/conts/retrieving.html or from the Cambridge Crystallographic Data Centre, 12 Union Road, Cambridge CB2 1EZ, UK; fax: (+44) 1223-336-033; or email: deposit@ccdc.cam.ac.uk. Experimental data such as IR and UV-Vis spectra, cyclic voltagram, EPR spectra at low temperature, ESI mass spectra, ${ }^{1} \mathrm{H}$ NMR of cleavage products, rate vs. substrate plot, Lineweaver-Burk plot, bond distance, bond angle \& H-bonded interaction parameters are available at www.ias.ac.in/chemsci.

\section{Acknowledgements}

BB sincerely thanks Science \& Engineering Research Board (SERB), a statutory body of Department of Science \& Technology (DST), New Delhi for the financial support under the START UP GRANT for YOUNG SCIENTIST (No. SB/FT/CS-088/2013 dtd. 21/05/2014). BB is greatly indebted to Prof. T.K. Paine, Department of Inorganic Chemistry, Indian Association for the Cultivation of Science, Kolkata, West Bengal, India for his valuable help in recording solid state EPR spectrum at 77 K. BB thanks Dr. Angshuman Roy Choudhury of IISER Mohali, Mohali 140 306, India for helping to collect crystallographic data of the copper complex.

\section{References}

1. (a) Kaim W and Schwederski B 1993 Bioanorganische Chemie, Teubner, Stuttgart Bioinorganic Catalysis J Reedijk (Ed.) (New York: Marcel Dekker); (b) Biswas B, Patra M, Dutta S, Ganguly M and Kole N 2013 Synthesis, structural characterization and biological activity of a trinuclear zinc(II) complex: DNA interaction study and antimicrobial activity J. Chem. Sci. 125 1445; (c) Dey D, Basu Roy A, Shen C-Y, Tsai H-L, Ranjani A, Gayathri L, Chandraleka S, Dhanasekaran D, Akbarsha M A, Kole N and Biswas B 2015 Synthesis and bio-catalytic activity of isostructural cobalt(III)-phenanthroline complexes J. Chem. Sci. 127 649; (d) Das S, Pasan J, Gayathri L, Saha S, Chandraleka S, Maji M, Dhanasekaran D, Akbarsha M A, Kole N and Biswas B 2016 Recognition of self-assembled water-nitrate cluster in a Co(III)2,2'-bipyridine host: synthesis, crystal structure, DNA cleavage, molecular docking and anticancer activity $J$. Chem. Sci. 1281755 
2. (a) Klinman J P 1996 Mechanisms whereby mononuclear copper proteins functionalize organic substrates Chem. Rev. 96 2541; (b) Dey D, Kaur G, Ranjani A, Gyathri L, Chakraborty P, Adhikary J, Pasan J, Dhanasekaran D, Choudhury A R, Akbarsha M A, Kole $\mathrm{N}$ and Biswas B 2014 A trinuclear zinc-schiff base complex: biocatalytic activity and cytotoxicity Eur. J. Inorg. Chem. 3350; (c) Chowdhury B, Patra M, Maji M and Biswas B 2015 Ligand centered radical pathway in catechol oxidase activity with a trinuclear zinc-based model: synthesis, structural characterization and luminescence properties Spectrochim. Acta Part A Mol Biomol. Spect. 144148

3. (a) Solomon E I, Sundaram U and Machonkin T E 1996 Multicopper oxidases and oxygenases Chem. Rev. 96 2563; (b) Biswas B, Al-Hunaiti A, Räisänen M T, Ansalone S, Leskelä M, Repo T, Chen Y-T, Tsai HL, Naik A D, Railliet A P, Garcia Y, Ghosh R and Kole N 2012 Efficient and selective oxidation of primary and secondary alcohols using an iron(III)/phenanthroline complex: structural studies and catalytic activity Eur. J. Inorg. Chem. 4479; (c) Pal A, Biswas B, Mitra M, Purohit C S, Hazra S, Kumar G S, Ghosh R 2013 Synthesis, Xray structure and DNA binding of a mononuclear iron(II) Schiff base complex J. Chem. Sci. 1251161

4. Magnus K A, Ton-That H and Carpenter J E 1994 Recent structural work on the oxygen transport protein hemocyanin Chem. Rev. 94727

5. Sa'nchez-Ferrer A, Rodri'guez-Lo'pez J N, Garc1'aCa'novas F and Garci'aCarmona F 1995 Tyrosinase: a comprehensive review of its mechanism Biochim. Biophys. Acta 11247

6. Gerdemann C, Eicken C and Krebs B 2002 The crystal structure of catechol oxidase: new insight into the function of type-3 copper proteins Acc. Chem. Res. 35 183

7. Fusetti F, Schröter K H, Steiner R A, van Noort P I, Pijning T, Rozeboom H J, Kalk K H, Egmond M R and Dijkstra B W 2002 crystal structure of the coppercontaining quercetin 2,3-dioxygenase from Aspergillus japonicus Structure $\mathbf{1 0} 259$

8. Steiner R A, Kooter I M and Dijkstra B W 2002 Functional analysis of the copper-dependent quercetin 2,3dioxygenase. 1. Ligand-induced coordination changes probed by X-ray crystallography: inhibition, ordering effect, and mechanistic insights Biochemistry 417955

9. Kooter I M, Steiner R A, Dijkstra B W, van Noort P I, Egmund M R and Huber M 2002 EPR characterization of the mononuclear $\mathrm{Cu}$-containing Aspergillus japonicus quercetin 2,3-dioxygenase reveals dramatic changes upon anaerobic binding of substrates Eur. J. Biochem. 2692971

10. Stewart L C and Klinman J P 1988 Dopamine betahydroxylase of adrenal chromaffin granules: structure and function Annu. Rev. Biochem. 57551

11. Prigge S T, Mains R E, Eipper B A and Amzel L M 2000 New insights into copper monooxygenases and peptide amidation: structure, mechanism and function Cell. Mol. Life Sci. 571236

12. Blackburn N J, Rhames F C, Ralle M and Jaron S 2000 Major changes in copper coordination accompany reduction of peptidylglycine monooxygenase: implications for electron transfer and the catalytic mechanism J. Biol. Inorg. Chem. 5341

13. Whittaker J W 2003 Free radical catalysis by galactose oxidase Chem. Rev. 1032347

14. Whittaker J W and Whittaker M M 1998 Radical copper oxidases: one electron at a time Pure Appl. Chem. 70903

15. Knowles P F and Ito N 1994 In Perspectives in Bioinorganic Chemistry (London: Jai Press) Vol. 2 p. 207

16. Halcrow M, Phillips S and Knowles P 2000 In Subcellular Biochemistry, 35, Enzyme-Catalyzed Electron and Radical Transfer A Holzenburg and N S Scrutton (Eds.) (New York: Plenum) 183

17. Whittaker M M, Kersten P J, Nakamura N, SandersLoehr J, Schweizer E S and Whittaker J W 1996 Glyoxal oxidase from phanerochaete chrysosporium is a new radical-copper oxidase J. W. J. Biol. Chem. 271 681

18. Whittaker M M, Kersten P J, Cullen D and Whittaker J W 1999 Identification of catalytic residues in glyoxal oxidase by targeted mutagenesis J. Biol. Chem. 27436226

19. Kosman D J, Hassett R, Yuan D S and McCracken J 1998 Spectroscopic characterization of the $\mathrm{Cu}$ (II) sites in the Fet 3 protein, the multinuclear copper oxidase from yeast required for high-affinity iron uptake J. Am. Chem. Soc. 1204037

20. Blackburn N J, Ralle M, Hassett R and Kosman D 2000 Spectroscopic analysis of the trinuclear cluster in the Fet3 protein from yeast, a multinuclear copper oxidase J. Biochemistry 392316

21. Palmer A E, Quintanar L, Severancee S, Wang T-P, Kosman D J and Solomon E I 2002 Spectroscopic characterization and $\mathrm{O}_{2}$ reactivity of the trinuclear $\mathrm{Cu}$ cluster of mutants of the multicopper oxidase Fet $3 p$ Biochemistry 416438

22. Nguyen H-H T, Nakagawa K H, Hedman B, Eliot S J, Lidstrom M E, Hodgson K O and Chan S I 1996 X-ray absorption and EPR studies on the copper ions associated with the particulate methane monooxygenase from Methylococcus capsulatus (Bath). $\mathrm{Cu}(\mathrm{I})$ ions and their implications J. Am. Chem. Soc. 11812766

23. Elliott S J, Randall D W, Britt R D and Chan S I 1998 Pulsed EPR studies of particulate methane monooxygenase from Methylococcus capsulatus (Bath): evidence for histidine ligation J. Am. Chem. Soc. 1203247

24. Nguyen H-H T, Elliot S J, Yip J H-K and Chan S I 1998 The particulate methane monooxygenase from Methylococcus capsulatus (Bath) is a novel copper-containing three-subunit enzyme isolation \& characterization $J$. Biol. Chem. 2737957

25. Lieberman RL, Shrestha D B, Doan P E, Hoffman B M, Stemmler T L and Rosenzweig A C 2003 Purified particulate methane monooxygenase from Methylococcus capsulatus (Bath) is a dimer with both mononuclear copper and copper-containing cluster Proc. Natl. Acad. Sci. U.S.A. 1003820

26. (a) Katz E 1967 Biosynthesis of secondary metabolites: roles of trace metals In Antibiotics II D Gottlieb D and P D Shaw (Eds.) p. 276 (New York: Springer); (b) McLain J, Lee J, Groves J T 2000 Biomimetic oxidations catalyzed by transition metal complexes In Biomimetic Oxidations Catalyzed by Transition Metal Complexes B Meunier (Ed.) (London: Imperial College 
Press); (c) Simándi T M, Simándi L I, Győr M, Rockenbauer A and Gömöry Á 2004 Kinetics and mechanism of the ferroxime (II)-catalysed biomimetic oxidation of 2aminophenol by dioxygen. A functional phenoxazinone synthase model Dalton Trans. 1056-1060

27. (a) Hollstein U 1974 Actinomycin. Chemistry and mechanism of action Chem. Rev. 74 625; (b) Simándi L I, Németh S and Rumlis N 1987 Study of the oxidation of 2-aminophenol by molecular oxygen catalyzed by cobalt (II) phthalocyaninetetrasodiumsulfonate in water J. Mol. Catal. 42357

28. (a) Butenandt A 1957 Über Ommochrome, eine Klasse natürlicher Phenoxazon-Farbstoffe Angew. Chem. 69 16; (b) Simándi TM, Simándi LI, Gyôr M, Rockenbauer A, Gömöry A, 2004 Kinetics and mechanism of the ferroxime (II)-catalysed biomimetic oxidation of 2aminophenol by dioxygen. A functional phenoxazinone synthase model J. Chem. Soc. Dalton Trans. 1056

29. (a) Cavill G W K, Clezy P S, Tetaz J R and Werner R L 1959 Synthesis of novel angular diazaphenoxazinone derivatives via palladium catalyzed Buchwald-Hartwig amidation protocols Tetrahedron 5 275; (b) Kaizer J, Csonka R and Speier G 2002 TEMPO-initiated oxidation of 2-aminophenol to 2-aminophenoxazin-3-one $J$. Mol. Catal. A: Chem. 18091

30. (a) Que L, Jr, Lipscomb J D, Münck E and Wood J M 1977 Protocatechuate 3,4-dioxygenase: inhibitor studies and mechanistic implications Biochim. Biophys. Acta 48560

31. (a) Ohlendorf D H, Lipscomb J D and Weber P C 1988 Structure and assembly of protocatechuate 3, 4dioxygenase Nature 336 403; (b) Solomon E I, Sundaram U M, Machonkin T E 1996 Multicopper oxidases and oxygenases Chem. Rev. 96 2563; (c) Ohlendorf D H, Orville A M and Lipscomb J D 1994 Structure of protocatechuate 3, 4-dioxygenase from Pseudomonas aeruginosa at $2.15 \AA$ A resolution J. Mol. Biol. 244 586; (d) Valley M P, Brown C K, Burk D L, Vetting M W, Ohlendorf D H and Lipscomb J D 2005 Roles of the equatorial tyrosyl iron ligand of protocatechuate 3, 4-dioxygenase in catalysis Biochemistry $4 \mathbf{4 1 0 2 4}$

32. (a) Youngme S, Phuengphai P, Chaichit N, Mutikainen I, Turpeinen U and Murphy B M 2007 Crystal structures and electronic properties of three fluxional [Cu(di-2-pyridylamine $\left.)_{2}(\mathrm{OXO})\right] \mathrm{Y}$ complexes $J$. Coord. Chem. 60 131; (b) Choudhury S R, Chen C-Y, Seth S, Kar T, Lee HM, Colaciu E and Mukhopadhyay S 2009 Anion- $\pi$ interaction stitching 2-D layers formed by self-assembly of cations of a mononuclear copper(II) complex: synthesis, crystal structure and magnetism of $\left[\mathrm{Cu}(\mathrm{OAc})\left(2,2^{\prime}-\text { dypam }\right)_{2}\right]\left(\mathrm{ClO}_{4}\right)[\mathrm{HOAc}=$ acetic acid, $2,2^{\prime}$-dypam $=2,2^{\prime}$-dipyridylamine $]$ J. Coord. Chem. 62 540

33. CrystalClear 2.0; Rigaku Corporation: Tokyo, Japan.

34. Sheldrick GM, 2008 Crystal structure refinement with SHELXL Acta Cryst. A 64112

35. Dolomanov O V, Bourhis L J, Gildea R J, Howard J A $\mathrm{K}$ and Puschmann H 2009 OLEX2: a complete structure solution, refinement and analysis program J. Appl. Cryst. 42339

36. (a) Paria S, Halder P and Paine T K 2010 A functional model of extradiol-cleaving catechol dioxygenases: mimicking the 2-his-1-carboxylate facial triad Inorg. Chem. 49 4518-4523; (b) De A, Garai M, Yadav H R, Choudhury A R and Biswas B 2017 Catalytic promiscuity of an iron (II)phenanthroline complex Appl. Organometal. Chem. 31 10.1002/aoc.3551

37. (a) Sawyer D T 1991 Oxygen Chemistry (New York: Oxford University Press); (b) Mialane P, Tehertanov L, Banse F, Sainton J and Girerd J 2000Aminopyridine iron catecholate complexes as models for intradiol catechol dioxygenases. Synthesis, structure, reactivity, and spectroscopic studies Inorg. Chem. 392440

38. Fereday R J, Hodgson P, Tyagi S and Hathaway B J 1981 The crystal structure and electronic properties of bis (2, 2' -bipyridyl)-copper (II) bis (hexafluorophosphate) $J$. Inorg. Nucl. Chem. Lett. 17243

39. De A, Dey D, Yadav H R, Maji M, Rane V, Kadam R M, Choudhury A R and Biswas B 2016 Unprecedented hetero-geometric discrete copper (II) complexes: crystal structure and bio-mimicking of Catecholase activity $J$. Chem. Sci. 1281775

40. (a) Mukherjee C, Weyhermuller T, Bothe E, Rentschler E and Chaudhury P 2007 A Tetracopper (II)-tetraradical cuboidal core and its reactivity as a functional model of phenoxazinone synthase Inorg. Chem. 46 9895; (b) Barry C E, Nayar P G and Begley T G 1989 A fungal metabolite mediates degradation of non-phenolic lignin structures and synthetic lignin by laccase Biochemistry 286323

41. (a) Chatterjee S, Sheet D and Paine T K 2013 An oxido-bridged diiron (II) complex as functional model of catechol dioxygenase Chem. Commun. 49 10251; (b) Balamurugan M, Vadivelu $\mathrm{P}$ and Palaniandavar $\mathrm{M}$ 2014 Iron (III) complexes of tripodal tetradentate 4N ligands as functional models for catechol dioxygenases: the electronic vs. steric effect on extradiol cleavage Dalton Trans. 4314653

42. (a) Ito M and Que L Jr. 1997 Angew. Chem. Int. Ed. Engl. 36 1342; (b) Dey D, De A, Yadav H R, Guin P S, Choudhury A R, Kole N and Biswas B 2016 ChemistrySelect 01 1910; (c) Dey D, Das S and Biswas B 2016 J. Indian Chem. Soc. 93495

43. Ito M and Que L Jr. 1997 Biomimetic extradiol cleavage of catechols: insights into the enzyme mechanism Angew. Chem. Int. Ed. Engl. 361342

44. Funabiki T, Mizoguchi A, Sugimoto T, Tada S, Tsuji M, Sakamoto H and Yoshida S 1986 Oxygenase model reactions. 1. Intra-and extradiol oxygenations of 3, 5-di-tert-butylcatechol catalyzed by (bipyridine)(pyridine) iron (III) complex J. Am. Chem. Soc. 108 2921

45. Die A, Gatteschi D and Pardi L 1993 Synthesis, characterization, and reactivity of catecholato adducts of iron(III) triaza- and tetraazamacrocyclic complexes:chemical evidence of the role of the metal ion in the oxidative cleavage Inorg. Chem. 321389

46. Pascaly M, Duda M, Rompel A, Sift BH, Meyer-Klaucke W and Krebs B 1999 Novel iron (III) complexes with imidazole containing tripodal ligands as model systems for catechol dioxygenases Inorg. Chim. Acta 291 289

47. Pascaly M, Nazikkol C, Schweppe F, Wiedemann A, Zurlinden K and Krebs B 2000 Structures and properties 
of novel mononuclear iron(III) complexes with benzimidazole containing tripodal tetradentate ligands $Z$. Anorg. Allg. Chem. 62650

48. Nishida Y, Shimo H and Kida S 1994 Synthesis, structural characterization, and extradiol oxygenation of ironcatecholato complexes with hydrotris (pyrazolyl) borate ligands J. Chem. Soc. Chem. Commun. 1611

49. Viswanathan R, Palaniandavar M, Balasubramanian T and Mutiah T P 1999 Functional models for catechol 1, 2dioxygenase. Synthesis, structure, spectra, and catalytic activity of certain tripodal iron (III) complexes Inorg. Chem. 372943

50. Pascaly M, Duda M, Schweppe F, Zurlinden K, Müller F $\mathrm{K}$ and Krebs B 2001 The systematic influence of tripodal ligands on the catechol cleaving activity of iron (III) containing model compounds for catechol 1, 2-dioxygenases J. Chem. Soc. Dalton Trans. 828

51. Dey D, Das S, Yadav H R, Ranjani A, Gyathri L, Roy S, Guin P S, Dhanasekaran D, Choudhury A R, Akbarsha M A and Biswas B 2016 Design of a mononuclear copper (II)-phenanthroline complex: catechol oxidation, DNA cleavage and antitumor properties Polyhedron 106 106

52. Speier G, Tyeklár Z, Szabo L, Tóth P, Pierpont C G and Hendrickson D N 1993 In The Activation of Dioxygen and Homogeneous Catalytic Oxidation D H R Barton, A E Martell and D T Sawyer (Eds.) (New York: Plenum Press) pp. 423-436 